\title{
НАЛОГОВЫЙ МАНЕВР В УПРАВЛЕНИИ РОСТОМ ДОХОДНОЙ ЧАСТИ БЮДЖЕТА
}

\author{
(c) 2020 Зельднер Алексей Григорьевич \\ доктор экономических наук, профессор, главный научный сотрудник \\ Институт экономики РАН, Россия, Москва
}

В статье подробно анализируется состояние налоговой системы нефтяного комплекса и проблемы, которые возникают при завершении налогового маневра, направленного на рост доходной части бюджета. Особое внимание уделяется налогу на дополнительный доход, радикально меняющий налогооблагаемую базу за счет перехода к налогообложению по финансовым результатам.

Ключевые слова: налоги, стимулирование, налоговый маневр, рентный налог, экспортные пошлины, акцизы, бюджет.

\section{Сущность налогового маневра}

С целью повышения отдачи от ТЭК в июне 2018 г. Госдума РФ констатировала необходимость завершения налогового маневра в нефтяной отрасли, включающего отмену экспортных пошлин на нефть и нефтепродукты в течение 6 лет и синхронный рост НДПИ, что может принести в бюджет 1-3 трлн. рублей за годы отмены [1].

Главной целью налогового маневра было ввести системный подход к субсидированию внутренней экономики и стран ЕАЭС. В июле 2018 г. Госдумой были приняты соответствующие поправки в Налоговый и Таможенный кодексы, определившие основные положения налогового маневра. Завершение налогового маневра рассчитано до 2024 г. Он включает постепенное снижение экспортных пошлин с одновременным повышением НДПИ, которым облагается вся добываемая нефть.

В «Основных направлениях бюджетной, налоговой и таможенно-тарифной политики на 2020 год и на плановый период 2021 и 2022 годы», подготовленных Минфином*, подчеркивается необходимость завершения нефтегазового маневра. На протяжении шести лет (2019-2024 гг.) предусмотрено «равномерное снижение экспортной пошлины на нефть и нефтепродукты с равнозначным повышением ставки НДПИ и введением объективных критериев для НПЗ, которым будет оказана финансовая поддержка через механизм предоставления отрицательного акциза». По мнению Минфина, это позволит обеспечить как модернизацию нефтеперерабатывающего сектора и обеспечение внутреннего рынка высококачественными нефтепродуктами, так и постепенный переход к единому топливному рынку на территории ЕАЗС. Введение в формулу отрицательного акциза на нефть демпфирующей компоненты в автоматическом режиме позволяет также регулировать уровень налоговой нагрузки при реализации нефтепродуктов на внутреннем рынке, что создает условия для поддержания стабильности цен на внутреннем рынке.

В процессе налогового маневра был увеличен налог на добычу полезных ископаемых и снижены экспортные пошлины, что привело к росту затрат для независимых, не входящих в ВИНК компаний и для наших соседей по ЕАЭС. В целом в результате налогового маневра бюджет получил дополнительные доходы от увеличения поступлений от НДПИ. Рост бюджетных доходов обеспечил и отказ от предоставления нефтяной таможенной субсидии в рамках ЕАЭС. Это почувствовала на себе и Беларусь. Практически при любом раскладе налоговый маневр обеспечивает выигрыш бюджета за счет того, что «увеличение НДПИ оказывается выше, чем снижение таможенных пошлин на нефть и нефтепродукты»**. Ожидалось, что демпфирующая надбавка обеспечит дополнительные выплаты бюджету. Но вмешался коронакризис 2020 г., произошел обвал мировых цен на нефть и нефтепродукты.

В процессе налогового маневра, сопровождавшегося снижением экспортным пошлин на нефть и ростом НДПИ, снизились и пошлины на нефтепродукты. Для поддержания НПЗ были снижены пошлины на светлые нефтепродукты и

\footnotetext{
* https://www.minfin.ru/common/upload/library/2019/10/main/ONBNiTTP_2020-2022.pdf

**https://vygon.consulting/upload/iblock/a5e/oilandgasjornal_ezhov_tyrtov.pdf
} 
повышены на темные, но это не обеспечило компенсаций в связи с тем, что «при сокращении размера пошлины на нефть сокращается и объем получаемой НПЗ таможенной субсидии*. Снижение субсидии равноценно удорожанию товара для последнего»**. Для поддержки финансово НПЗ, из-за снижения субсидирования переработки, вводится обратный акциз на нефть. Обратный акциз предоставляется не всем НПЗ, а только тем, кто находится под санкциями, кто заключает инвестиционные соглашения на модернизацию и для поставщиков на внутренний рынок бензина класса Евро-5 или нафту в объеме не менее $10 \%$ от выпуска.

Налоги в структуре доходной части бюджета. Нефтегазовый сектор - важнейший источник пополнения доходной части федерального бюджета. В его структуре в 2019 г. нефтегазовые доходы составили 40,8\%. Это 18,4\% ВВП ${ }^{* * * *}$ В структуре консолидированного бюджета удельный вес налогов ТЭК ниже

В структуре налоговых платежей до 2014 г. преобладали экспортные пошлины, затем приоритет в связи с законодательными изменениями перешел к НДПИ (рентный налог на добычу полезных ископаемых, рост которого связан и с увеличением добычи нефти). Кроме названных, федеральные налоги включают акцизы и налог на дополнительный доход от добычи углеводородного сырья (НДД).

Удельный вес дохода от НДПИ начиная с 2010 г., устойчиво растет, достигнув в среднем 3,4\% ВВП. Что касается вывозных таможенных пошлин на нефтепродукты, то они не превышают $2 \%$ и повторяют тенденцию нефтяных пошлин. Если НДПИ - налог, позволяющий государству изымать нефтяную ренту, то экспортная пошлина на продукцию ТЭК в основном носит фискальный характер и по своей экономической сущности не связана с рентным доходом. Постепенный отказ от экспортной пошлины в связи с завершением налогового маневра способствует снижению цен на нефть, идущую на переработку. При этом полученные в процессе переработки на НПЗ нефтепродукты также облагались пошлиной, но на более низком уровне в размере 30\% от пошлины на нефть. Снижение пошлины повышает привлекательность экспорта нефти и оказывает влияние на рост мировых цен (нетбэк). Поэтапное сокращение экспортной пошлины на нефть и нефтепродукты, вплоть до ее обнуления в 2024 г., связано с модернизацией формулы ее расчета, уменьшающим спецкоэффициентом, который будет ежегодно снижаться на 0,167 (в январе 2019 г. он составлял 0,833). Налоговая ставка будет снижаться в следующей последовательности: в 2019 г. до 25\%, в 2020 г. до $20 \%$ и далее ежегодно по 5\%, вплоть до обнуления в 2024 г.

Таможенные пошлины были направлены на поддержку НПЗ, соответственно и потребителей. С отменой пошлины для поддержки НПЗ вводится отрицательный акциз на нефть. Для его расчета вводится такое понятие подакцизного товара как нефтяное сырье (вся купленная нефть на отечественном рынке для переработки). При условии соблюдения установленного норматива такой нефти в процентах от добытой компании начисляется дополнительный акциз, он не выплачивается, а используется как взаимозачет, уменьшая общую сумму налогов. Акциз рассчитан на крупные холдинги замкнутого типа

\footnotetext{
* Лишение НПЗ субсидий приводит к их финансовым потерям. Так в расчете на 2017 г. НПЗ на субсидиях сэкономили 1,4 трлн. руб. при потерях из-за пошлин 782 млрд. руб. (https://finanse.rambler.ru/ economics/44437536-prodolzhayut-zalivat)

** https://zen.yandex.ru/media/id/5c59b64fdefde400ad8ed83c/filipp-muradian-ceny-na-toplivo-v-rf-ne-snijalis-vperiody-nizkih-cen-na-neft-5ca6006b7201b500b2fc058d

В своем интервью аналитик по корпоративным рейтингам «Эксперт РА» Ф. Мурадян отметил, что «рост цен на топливо на экспортных рынках, который связан с ростом мировых цен на нефть, в условиях стабильного валютного курса приводят в автоматическом режиме к росту цен на топливо в стране».

**** Расчет по материалам: Основные направления бюджетной, налоговой и таможенно-тарифной политики на 2019 год и на плановый период 2020 и 2021 годов» [Электронный ресурс]. http://www.consutant.ru. С. 52

**** В структуре доходов консолидированного бюджета за 2018 г. налоги, сборы и регулярные платежи за пользование природными ресурсами составили 6,2 трлн. рублей, это 5,9\% общей суммы доходов. Большая часть этих налогов получена от функционирования ТЭК. (Россия в цифрах. 2019. Росстат.М. 2019. С. 422).

****** НДПИ достаточно весомый налог, связанный с изъятием нефтяной ренты, он в отдельные годы достигает по сумме (в 2018 г.), по оценке А. Кудрина, до 10\% ВВП. https://www.vedomosti.ru/opinion/articles/2020/07/14/834 592-promisshlennaya-politika-vmesto-reform
} 
(ВИНК), но используется и для независимых НПЗ. Для недопущения резкого роста цен вводится демпферный механизм*. Демпфер рассчитывается, как разница между мировой ценой на бензин и условной внутренней ценой, устанавливаемой правительством на год, (учитывая прошлые рыночные тенденции) с учетом соответствующего коэффициента (в 2020 г. коэффициент на бензин составляет 68\%, по дизтопливу 65\%). При превышении мировых цен над внутренними разница с учетом коэффициентов компенсируется государством и наоборот. Но в этом случае возникает проблема с возможным ростом цен на АЗС. Условная цена назначается правительством на год и не меняется при изменении ценовой конъюнктуры, она индексируется в следующем году на 5\%. В этом одна из причин того, что в условиях резкого снижения мировых цен на нефть, в России внутренние цены остаются без изменений, они растут за счет инфляции и акцизов.

Акциз. Акциз, как косвенный налог, охватывает товары массового потребления внутри страны. Акциз включается в стоимость товара и отражается на бюджете потребителей. Как федеральный налог, он уплачивается производителями федеральной налоговой службе. Налоговая база при реализации товаров согласно статье 187 НК РФ определяется отдельно по каждому виду подакцизных товаров в зависимости от установленных налоговых ставок.

Акцизы** на автомобильный бензин, дизтопливо, моторное масло по нормативу $12 \%$ введен федеральным законом № 145-ФЗ от 23.05.2016. Что касается акциза на нефтяное сырье, направляемое на переработку, то он в соответствии с федеральным законом № 456-ФЗ от 28.11.2018 установлен в размере 100\%. До 2018 г. рост акцизов, как правило, не превышал уровня инфляции, но с января 2018 г. вырос сразу на 10,7\% (до 11,2 тыс. руб. за тонну бензина «Евро-5» и также за тонну дизтоплива). Официальное объяснение правительства: необходимость средств для строительства автотрасс - калининградской «Приморского кольца» и крымской «Тавриды».
С завершением налогового маневра суть акцизной политики практически не меняется. Акцизы в России на автобензин класса 5, на дизтопливо, на моторное топливо растут ежегодно в рамках прогнозируемой инфляции (исключение - автобензин, не соответствующий 5 классу и прямогонный бензин).

Переход к налогообложению в нефтегазовой сфере по финансовым результатам

Крупнейшие нефтяные компании России ПАО «НК Роснефть», «Лукойл», «Газпромнефть» и др., осуществляют полный цикл деятельности в нефтяной сфере,- добычу, переработку, экспорт, внутреннюю реализацию через свои АЗС. Причем структура полного цикла у разных компаний складывается по-разному и в значительной мере это связано с ориентацией компаний на внешний или внутренний рынок. Такая ориентация приводит к тому, что «корпоративные налоги (налог на прибыль, на имущество, начисления на фонд оплаты), составляют, например, в такой компании, ориентированной на экспорт, как ПАО «НК «Роснефть», всего 8\% общего налогового бремени ${ }^{* * * *}$.

Следует учесть, что налогообложение зарубежных нефтегазовых компаний в основном, в отличие от российских, строится на налогообложении финансовых результатов. Для зарубежных компаний основу налоговой нагрузки составляет налог на прибыль и отраслевые налоги. В среднем «за 2010-2016 гг. доля налога на прибыль в структуре налоговой нагрузки у компаний Shell, Exxon, BP составила 65\%» (Жаворонкова Е. 2019). В России также предпринята попытка перевода налоговой системы нефтегазовой отрасли на финансовые результаты. Для этого в тестовом режиме на различных участках недр введен налог на дополнительный доход (НДД).

\section{Налог на дополнительный доход (НДД)}

Налоговая система нефтегазовой отрасли постоянно находится в стадии совершенствования. Первоначально большинство стран с целью расширения ресурсной базы стимулировали рост объемных показателей, вводя соответству-

\footnotetext{
* Более подробно в статье: ЗельднерА.Г.Демпфер как механизм управления ценообразованием на топливные ресурсы. Финансовая экономика. № 5 ч. 3. 2020. С. 271-274

** В соответствии с Федеральными законами № 120 от 20.08.2004 и № 307 от 2.08.2019 субъекты РФ обязаны устанавливать дифференцированные отчисления в местный бюджет не менее $10 \%$ налоговых доходов от акциза на бензин и другие продукты переработки нефти.

*** Жаворонкова Е. Налоговая нагрузка компаний нефтяной отрасли в России и за рубежом. Государственное управление. Электронный вестник. М. МГУ. Выпуск № 78. 02.2020. С. 8-9.
} 
ющие налоговые льготы. Но по мере наращивания количественных показателей многие страны мира переносят акцент в налогообложении на финансовые результаты. Основная цель НДД предполагает замену налогов, построенных на объемных показателях, и переход на налогообложение финансовых результатов, получаемых от нефти. Введенный в порядке эксперимента с 2019 г. налог на дополнительный доход от добычи углеводородного сырья (НДД) (глава $25.4 \mathrm{Ha-}$ логового кодекса РФ) так определяет НДД: этот налог «начисляется на сумму дополнительного дохода от добычи углеводородного сырья на каждом участке недр, который рассчитывается как положительная разница между полученными на этом участке недр доходами и расходами. В случае, если размер минимального налога по участку недр больше чем сумма налога, рассчитанного как разница между доходами и расходами этого участка, то налогом на дополнительный доход от добычи углеводородного сырья признается минимальный налог»".

Минимальный налог рассчитывается как соответствующая налоговой ставке процентная доля минимальной налоговой базы. Минимальная налоговая база определяется как величина расчетной выручки от реализации углеводородного сырья на участке недр за налоговый (отчетный) период, последовательно уменьшенная на расходы (расчетные и фактические) на участке недр. Сумма налога на дополнительный доход будет уменьшать налогооблагаемую базу для расчета налога на прибыль. Для ограничения возможности завышения затрат при расчете НДД вычитаемые расходы ограничиваются суммой в 9520 руб./т добытого сырья с учетом показателя инфляции. Ставка НДД составляет $50 \%$ доходов, полученных от реализации нефти, что, по замыслу, стимулирует добычу нефти уже на использованных и новых месторождениях и уменьшает базу для расчета налога на прибыль. Но при этом НДПИ не отменяется, но снижается. То есть компании выплачивают как НДД, так и НДПИ. И, как показывают расчеты, по некоторым месторождениям рентабельность выше за счет использования НДД, «чем просто платить НДПИ по полной ставке»***.

Введенный в пилотном режиме налог на дополнительный доход для новых и уже выработанных месторождений с целью интенсифицировать их лучшее использование и повышение доходности предполагает снижение налоговой нагрузки для углеводородного сектора, что, по замыслу, может привлечь дополнительные инвестиции. Проведение эксперимента по введению НДД поставило ряд проблем как положительного, так и отрицательного плана.

K положительным моментам можно отнести: 1) налоговые каникулы в отношении новых месторождений и месторождений с трудноизвлекаемыми запасами; 2) по сути, предлагается до окупаемости проекта обеспечить снижение налоговой нагрузки ниже размера действующей, «что позволит сократить объемы кредитов, повысить рентабельность и выйти на самоокупаемость». К отрицательным моментам следует отнести: 1) сохранение наряду с НДД и налога на добычу полезных ископаемых; 2) методологическую неотработанность раздельного учета расходов и доходов по каждому участку недр, распределение косвенных расходов и др. По данным специалистов группы КПМГ по оказанию налоговых услуг компаниям нефтегазового сектора «государство с помощью регулирования тарифов для расчета расходов получает возможность фиксировать поступления в бюджет без привязки к экономике проектов. Кроме того, выручка при расчете налоговой базы определяется расчетным путем, таким образом, факт реализации углеводородного сырья (УВС) в расчет не принимается» ${ }^{* * *}$.

Разработанный Минфином пилотный проект охватил четыре различные группы месторождений нефти и газа с характерными признаками выработанности и налоговых льгот. Группа с наибольшей добычей, около 26 млн. т в год, куда вошли «Роснефть» И «Газпромнефть» - вторая в рейтинге. Именно на эту группу пришлась основная сумма добавочной прибыли, которая, по мнению Минфина, и обеспечила выпадающие

\footnotetext{
* https://www.nalog.ru/rn77taxation/taxes/ndd

НК РФ Глава 25.4. Налог на дополнительный доход от добычи углеводородного сырья (введена Федеральным законом от 19.07.2018 № 199-Ф3). Налоговый кодекс Российской Федерации (часть вторая) от 05.08.2000 № 117 Ф3 (ред. от 08.06.2020 (с изм. и доп., вступ. в силу с 01.07.2020)

** https://iz.ru/1035046/dmitrii-grinkevich/kompensatciia-fakta-minfin-podgotovil-nalogovuiu-reformuneftegazovoi-otrasli

*** https://oilcapital.ru/article/general/1 4-03-2018/chto-nam-gotovit-ndd
} 
доходы бюджета.

Некоторые итоги эксперимента по введению НДД подвел в своем интервью замминистра финансов А.Сазанов в июне 2020 г. Он отметил, что введение НДД в России лишило бюджет 213 млрд. руб. дохода в 2019 г.*. По данным А.Сазанова, сумма выпадающих из-за режима НДД поступлений 213 миллиардов рублей, сопоставима со стоимостью налоговых каникул для пострадавшего от пандемии малого и среднего бизнеса за два квартала. «Простая экстраполяция цифр говорит о том, что если пойти на широкое введение НДД, бюджет недополучит 2 триллиона рублей. Распространение НДД на всю отрасль равносильно снижению цены на нефть в сегодняшних реалиях до $\$ 25$ за баррель. В таких условиях бюджет протянет года 2-3, в лучшем случае, 5-7 лет. ... В 2017 году, когда мы обсуждали НДД, нам говорили - это очень правильный режим, вырастут инвестиции. Мы ввели его на площади, обеспечивающей $10 \%$ добычи, но инвестиции не увеличились ни на рубль. У ТОП-5 нефтяных компаний абсолютно никак не изменились инвестиции, разница - ноль. А вот дивиденды за это время выросли в два раза - на 500 миллиардов рублей»***. По данным замминистра А. Сазанова, курирующего нефтяную отрасль, в современных условиях «на выработанном месторождении, где самая высокая себестоимость добычи, свободный денежный поток (после уплаты НДПИ и экспортной пошлины, но до уплаты налога на прибыль) составит порядка \$7-8 за баррель по сравнению с \$13-15 в прошлом году».

Потери бюджета от введения налога на дополнительный доход, оцененные Минфином, существенно напрягли министерство. В этой связи Минфин подготовил законопроект, направленный на возврат в течение нескольких лет выбывших в 2019 г. доходов бюджета.

Как мы уже отмечали, бюджет потерял при расчетах НДД в 2019 г. 213 млрд. руб. Минфин хочет вернуть в бюджет эту сумму за счет отказа от понижающих коэффициентов и введения повышающего коэффициента, чтобы за 20212023 гг. обеспечить бюджет дополнительным доходом примерно в 200 млрд. руб. Пилотный проект готовил Минфин и ему исправлять свои методические ошибки. И потом это годичный эксперимент, при реализации которого априори сохраняются риски. Эксперимент многообещающий и его следует продолжить, введя изменения в методику и отказавшись от конфискационных действий в отношении нефтяных предприятий, получивших прибыль.

Методологическая ошибка заключается в подходе к оценке выпадающих доходов. В момент перехода на эксперимент по НДД, а это был 2018 г. «оценка выпадающих доходов проводилась при цене нефти 40 долл. за баррель, а реальная цена в 2019 г. составила 63,5 долл./бар., что увеличило объем выпадающих доходов примерно вдвое». Но вследствие коронакризиса в 2020 г. вряд ли средняя цена на нефть достигнет уровня 2018 г. В принципе следовало бы ввести дифференцированный коэффициент, меняющийся при расчете НДД в зависимости от средней стоимости нефти, заложив в методику условия применения понижающего и повышающего коэффициентов при расчете НДД.

По мнению директора департамента налогов и права Deloitte Юлии Меньшиковой, законопроект Минфина предусматривает увеличение налоговой нагрузки на компании, «что, конечно же, может негативно повлиять на рентабельность тех проектов, которые уже находятся в активной стадии добычи. С другой стороны, отмечает она, учитывая текущие низкие цены на нефть и избыток ее предложения, данные изменения могут также отражать временное снижение интереса государства к развитию новых проектов по добыче нефти и стимулированию ее роста $)^{* * * *}$.

Налог на добычу полезных ископаемых начисляется на выручку от реализации объема добытой нефти, при этом понесенные затраты в расчет не принимаются. Вводимый в качестве эксперимента налог на дополнительный доход устанавливает налоговую базу по разнице между выручкой и затратами, связанными с добычей и транспортировкой нефти. Это позволяет использовать и более затратные трудноизвлекаемые нефтесодержащие участки. НДД, если он будет доработан и упрощен, позволит перераспределить налоговую нагрузку, «перенести ее основную часть на более поздние этапы разработки месторождений, по сути, после выхода их

\footnotetext{
*https://ru.reuters.com/article/businessNews/idRUKBN23M1PD-ORUBS

** Там же.

*** Барсуков Ю., Козлов Д.Добыча полезных облагаемых. Коммерсант. 3.08.2020. https://www.kommersant.ru/ doc/4441359
} 
на проектную мощность».

Заключение. В процессе перехода от плановой к рыночной экономике вместо перехода на современный инновационный путь промышленного развития в России сложившаяся олигархическая прослойка пошла по пути наименьшего сопротивления, введя вместо «новой индустриализации» сырьевую модель развития. И, несмотря на благоприятную конъюнктуру мировых цен на продукцию ТЭК, крупные нефтяные компании все 30 лет после слома плановой системы беспрерывно повышали цены на топливо (соответственно росли тарифы) для населения.
Основная масса полученной прибыли оседала в оффшорах, но не работала на модернизацию и инновационное развитие страны. Возникший в 2020 году, вызванный коронавирусом, мировой кризис показал ошибочность сырьевой модели. По сути, выпадающие доходы от падения экспорта продукции ТЭК всерьез и надолго. Наступают и достаточно активно альтернативные источники энергии и экологические проблемы. Необходимы структурные реформы, новая индустриализация на новейшей технологическоинновационной основе.

\section{Библиографический список}

1. Ежов С., Тыртов Е. Налоговый маневр... или тупик? Oil\&Gas Journal Russia. https://vygon.consulting/upload/ iblock/a5e/oilandgasjornal_ezhov_tyrtov.pdf

2. Основные направления бюджетной, налоговой и таможенно-тарифной политики на 2019 год и на плановый период 2020 и 2021 годов» http://www.consutant.ru.

3. Россия в цифрах. 2019. Росстат.М. 2019.

4. https:/www.vedomosti.ru/opinion/articles/2020/07/14/834592-promisshlennaya-politika-vmesto-reform

5. Зельднер А.Г. Демпфер как механизм управления ценообразованием на топливные ресурсы. Финансовая экономика. № 5 ч. 3. 2020.

6. Федеральные законы № 120 от 20.08.2004 и № 307 от 2.08.2019

7. Жаворонкова E. Налоговая нагрузка компаний нефтяной отрасли в России и за рубежом. Государственное управление. Электронный вестник. М. МГУ. Выпуск № 78. 02.2020.

8. https://www.nalog.ru/rn77taxation/taxes/ndd

9. https://ru.reuters.com/article/businessNews/idRUKBN23M1PD-ORUBS

10. Барсуков Ю., Козлов Д. Добыча полезных облагаемых. Коммерсант. 3.08.2020. https://www.kommersant.ru/ doc/4441359 